\title{
Subjective Word-Finding Difficulty Reduces Engagement in Social Leisure Activities in Alzheimer's Disease
}

\author{
Meagan T. Farrell, PhD, Laura B. Zahodne, PhD, Yaakov Stern, PhD, Jhedy Dorrejo, MS, \\ Philip Yeung, and Stephanie Cosentino, PhD
}

OBJECTIVES: To assess the influence of subjective wordfinding difficulty on degree of engagement in social leisure activities among individuals with Alzheimer's disease (AD).

DESIGN: Analysis of data collected from the second cohort of the Multicenter Study of Predictors of Disease Course in Alzheimer's disease.

SETTING: Four study sites in the United States and France.

PARTICIPANTS: Individuals diagnosed with mild to moderate $\mathrm{AD}(\mathrm{N}=236)$.

MEASUREMENTS: On separate questionnaires, participants were asked to 1) report whether they had trouble finding the right word when speaking (subjective wordfinding difficulty) and 2) rate their frequency and enjoyment of social and nonsocial leisure activities. Objective language measures included object naming and verbal fluency. Measures of dependence, depression, cognitive status, age, sex, and education were also included as covariates in regression analyses.

RESULTS: Fifty-two percent of the sample reported word-finding difficulty, and subjective complaints were correlated with poorer verbal fluency scores. Subjective word-finding difficulty was selectively related to social but not nonsocial activity measures. Endorsers of word-finding difficulty reported less frequency and enjoyment of social leisure activities, controlling for effects of covariates and objective word-finding ability. In contrast, lower engagement in nonsocial activities was associated with older age and higher depression scores but not with word-finding complaints. Caregivers' reports of study participants' activities corroborated these results.

CONCLUSION: Individuals with $\mathrm{AD}$ who are aware of increasing word-finding failures are less likely to

From the Cognitive Neuroscience Division, Department of Neurology and Taub Institute for Research on Alzheimer's Disease and the Aging Brain, College of Physicians and Surgeons, Columbia University, New York, New York.

Address correspondence to Meagan Farrell, Cognitive Neuroscience Division, Department of Neurology, Columbia University College of Physicians \& Surgeons, 630 West 168th Street, P \& S Box 16, New York, NY 10032. E-mail: mtf2127@columbia.edu

DOI: $10.1111 /$ jgs. 12850 participate in and enjoy socially oriented leisure activities. This finding may have significant implications for clinical and health outcomes in AD. Failure to evaluate subjective language complaints could result in social withdrawal symptoms, threatening the individual's quality of life and increasing caregiver burden. Reduced social interaction may ultimately exacerbate language symptoms over time. J Am Geriatr Soc 62:1056-1063, 2014.

Key words: subjective language complaints; Alzheimer's disease; leisure activities

W ord-finding difficulty is one of the most ubiquitous and distressing cognitive problems reported in older adulthood. ${ }^{1-4}$ These experiences often present as tip-ofthe-tongue (TOT) states, in which a speaker is momentarily unable to retrieve the lexical representation of a word, despite a frustrating feeling that the word is known and just beyond reach. ${ }^{5}$ Perhaps because of the social salience of word retrieval, researchers have alluded to a connection between impaired word-finding and lack of communicative confidence in late life. ${ }^{6-9}$ In turn, lack of confidence could constrain older adults' desire to engage in socially oriented activities. $^{8}$

The frequency of word-finding failures is even higher with dementia than in normal aging. ${ }^{10-13}$ Because of its pervasiveness, word-finding difficulty may be among the most functionally and socially debilitative symptoms associated with dementia, ${ }^{14}$ but the consequences of subjective (self-reported) word-finding difficulty on the well-being of individuals with dementia have not been formally examined. The current study investigated the prevalence of subjective word-finding difficulty in 236 individuals with mild to moderate Alzheimer's disease (AD). The primary question of interest was whether subjective word-finding complaints predicted individuals' participation in and enjoyment of social leisure activities, independent of disease severity, depression, and demographic variables. The specificity of this relationship was 
tested by comparing the effect of word-finding complaints on social activities with their effect on nonsocial leisure activities.

A number of studies have suggested that subjective cognitive complaints foreshadow subsequent cognitive decline $^{15,16}$ and are correlated with $\mathrm{AD}$ biomarkers and neuropathology. ${ }^{17-21}$ These studies have primarily focused on memory complaints or have examined summed totals of cognitive complaints without dissociating the effect of specific cognitive domains. As a result, little is known about the frequency with which particular types of language complaints are experienced after $\mathrm{AD}$ diagnosis or how individuals' perceptions regarding their language declines influence disease outcomes.

Of particular interest is whether subjective language complaints influence social aspects of quality of life, which is one of the most important factors to consider after a dementia diagnosis. ${ }^{22}$ Although several factors are considered essential components of quality of life, ${ }^{23}$ the positive effect of stimulating leisure activities on quality of life and cognitive status is well documented. ${ }^{24,25}$ Moreover, behavioral intervention studies have demonstrated a beneficial effect of meaningful activities on the emotional well-being of individuals and caregivers. ${ }^{26,27}$ As such, identifying the cognitive, behavioral, and psychosocial factors that predict engagement in leisure activities may have important consequences for a number of health outcomes relevant for healthy aging and dementia.

In $\mathrm{AD}$, less participation in enjoyable activities has been linked to depressive affect, cognitive decline, dependence, and personality change. ${ }^{28,29}$ The association between subjective cognitive problems and likelihood of engaging in pleasant leisure activities has not been examined. Given the distress attached to word-finding problems, it is intuitive that self-perceived problems in the ability to retrieve words may selectively relate to socially oriented activities (e.g., getting together with friends, attending church groups), as opposed to leisure activities that can be performed without social interaction (e.g., crafts, gardening).

The goal of the present study was to examine the relationship between self-reported word-finding difficulty and participation in and enjoyment of various leisure activities in individuals with AD. It was hypothesized that subjective word-finding difficulty would relate to measures of social activity engagement in addition to other explanatory variables. This relationship would presumably stem from individuals' declining confidence in their ability to have successful conversations, resulting in an avoidance of leisure activities that require social interaction. However, it is possible that individuals with word-finding difficulty might possess certain personality or cognitive characteristics that render them less likely to participate in any type activity. To assess the specificity of the relationship between perceived word-finding difficulty and social activities, the same independent variables were used to predict engagement in nonsocial activities. It was hypothesized that nonsocial activity engagement would be related to indices of disease severity, age, and depression but would not be related to subjective word-finding difficulty because of the lack of expressive language demands.

\section{METHOD}

\section{Participants}

The sample included participants recruited in the second wave of the Multicenter Study of Predictors of Disease Course in Alzheimer's Disease (Predictors Study), a longitudinal study examining biological and lifestyle markers of $\mathrm{AD}$ progression. The full cohort included individuals diagnosed with probable $\mathrm{AD}$ according to the National Institute of Neurological and Communicative Diseases and Stroke/Alzheimer's Disease and Related Disorders Association criteria. Study recruitment occurred at four study sites: Columbia University $(\mathrm{N}=102)$, Johns Hopkins University $(\mathrm{N}=63)$, Massachusetts General Hospital $(\mathrm{N}=63)$, and Hôpital de la Salpêtriére $(\mathrm{N}=38)$. Details regarding this study's procedures and participants have previously been published. ${ }^{30}$ In brief, participants were recruited from memory clinics at each of the study sites. The diagnosis of probable AD was made in the clinic setting and was based on a full neuropsychological examination plus additional neurological and medical evaluations. Exclusion criteria included stroke, history of alcohol dependence, recent or extensive electroconvulsive treatments, and clinical evidence of schizophrenia before the onset of cognitive decline. In the Predictors Study, trained research assistants administered scales, questionnaires, and cognitive tests during home visits, and participants were evaluated every 6 months for up to 5 years At each visit, information was gathered about cognitive function, dependence, various psychiatric and neurological symptoms, medical treatments, medications, living conditions, and other lifestyle factors.

The current study is restricted to baseline data from participants' initial visit. Participants were required to have mild to early-moderate dementia at the initial visit, as defined by a score of 16 or greater on the Folstein MiniMental State Examination (MMSE). ${ }^{31}$ Twenty-two participants from the cohort were removed from the current study because they were missing the main independent variable (subjective word-finding difficulty). These participants did not differ from the current sample in terms of global cognitive status, levels of depression or dependence, or demographic characteristics. The demographic characteristics of the 236 participants included in the analyses are shown in Table 1.

\section{Measures}

\section{Leisure Activity Scores}

Estimates of the participants' participation in various leisure activities were derived from a modified version of the Pleasant Events Schedule-AD (PES-AD). ${ }^{32}$ The full (53item) PES-AD and its shortened version have been shown to have strong psychometric validity, as well as high agreement between the full scale and shortened versions. ${ }^{28}$ The scale includes versions for participants and caregivers (who answer questions about the participant's activities) and consists of items regarding the participant's participation in 15 leisure activities. For each activity, the respondent is 


\section{Table 1. Sample Characteristics}

\begin{tabular}{lccc}
\hline \multicolumn{1}{c}{ Characteristic } & Value & $\begin{array}{c}\text { Sample } \\
\text { Range }\end{array}$ & $\begin{array}{c}\text { Scale } \\
\text { Range }\end{array}$ \\
\hline Age, mean \pm SD & $76.0 \pm 7.8$ & $53-95$ & \\
$\begin{array}{l}\text { Modified Mini-Mental State } \\
\text { Examination score, mean } \pm \text { SD }\end{array}$ & $38.4 \pm 6.4$ & $22-52$ & $0-57$ \\
$\begin{array}{l}\text { Female, \% } \\
\text { Education, years, mean } \pm \text { SD }\end{array}$ & 62.0 & & \\
$\begin{array}{l}\text { Ethnicity, \% } \\
\quad \text { White }\end{array}$ & $92.6 \pm 3.4$ & $5-20$ & \\
Black & 6.2 & - & \\
$\quad$ Other & 0.8 & - & \\
$\quad$ Unknown & 0.4 & - & \\
Brief Symptom Inventory & $9.7 \pm 3.5$ & $7-25$ & $0-35$ \\
$\begin{array}{l}\text { Depressive Subscale, } \\
\text { mean } \pm \text { SD }\end{array}$ & & & \\
$\begin{array}{l}\text { 13-item Dependence Scale, } \\
\text { mean } \pm \text { SD }\end{array}$ & $5.2 \pm 2.2$ & $0-12$ & $0-16$ \\
\hline
\end{tabular}

$\mathrm{SD}=$ standard deviation

asked to indicate how often the participant participated in the activity within the past month $(0=$ none, $1=$ few, $2=$ often) and whether the participant enjoyed this activity $(0=$ no, $1=$ yes $)$.

Social and nonsocial activity composite scores were extracted from the full questionnaire. Items were included in the social composite if the activity elicited expressive communication. All items that lacked communicatory demands were included in the nonsocial composite. One item was added to both composite scores because the description of the activity contained a social component (playing games or cards) and a nonsocial component (doing crosswords or puzzles). This procedure resulted in a 6-item social composite and a 10-item nonsocial composite (Table 2). Separate sum scores for frequency and enjoyment were computed for both composites. Possible scores

Table 2. Items in the Social and Nonsocial Activity Composites

\section{Social Composite}

Getting together with

family and friends

Talking to family and

friends on the phone

Going to movies, museums,

entertainment

Going to church, synagogue,

religious events

Playing games or cards, and/or

doing crosswords, puzzles

Going shopping for groceries,

clothes, etc.

\section{Nonsocial Composite}

Being outside, going for walks,

enjoying nature

Being with pets or animals, watching animals

Listening to radio, tapes, or watching television

Playing games or cards, doing crosswords or puzzles

Gardening, plant care, indoors or outdoors

Completing a difficult task

Going for a ride in car, train, or bus

Reading or having stories read to him or her

Doing handiwork or crafts

Exercising, playing or watching sports for social activities were 0 to 12 for frequency and 0 to 6 for enjoyment. For nonsocial activities, possible scores were 0 to 20 for frequency and 0 to 10 for enjoyment. Higher scores correspond to greater participation or enjoyment.

\section{Word-Finding Ability}

Subjective Word-Finding Difficulty. Participants and caregivers were asked in separate questionnaires to indicate whether the participant had "trouble finding the right word when talking" $(0=$ no, $1=$ yes $)$. Fifty-two percent of participants endorsed word-finding difficulty, and $48 \%$ of caregivers indicated that the participant experienced trouble with word finding. Details regarding agreement between participant and caregiver reports are described below. Participant perception of word-finding difficulty is the primary independent variable used in this study.

Objective Word-Finding Ability. Objective word-finding ability was assessed using three different measures: a 30 -item version of the Boston Naming Test ${ }^{33}$ (an assessment of visual confrontation naming), letter fluency ${ }^{34}$ (participants are asked to generate as many words as they can beginning with the letter $\mathrm{C}, \mathrm{F}$, or $\mathrm{L}$ within 60 seconds), and category fluency ${ }^{34}$ (participants are asked to generate as many animals as they can think of within 60 seconds).

\section{Covariates}

A number of additional variables were considered as potential covariates for regression models predicting leisure activities (Table 1 for descriptive statistics). Demographic variables included age (continuous), sex $(0=$ male, $1=$ female), and education (number of years of formal education completed).

Dependence. Caregivers completed a 13-item Dependence Scale ${ }^{35}$ to assess participants' level of reliance on care. Items addressed concerns associated with mild impairment (e.g., Does the participant need help to remember appointments?) to severe impairment (e.g., Does the participant need to be tube fed?). For two questions pertaining to mild impairment, the caregiver was asked to indicate how often the participant required aid, never (0), occasionally (1), or frequently (2). For all other questions, they responded with no (0) or yes (1). A participant's dependence score represented the sum of all 13 items. Possible scores were 0 to 16 , with higher scores corresponding to greater dependence.

Global Cognition. Global cognitive function was assessed using the modified Mini-Mental State Examination (mMMS), which includes all items from the MMSE plus supplementary items used to assess digit span, attention and calculation, semantic knowledge, language, and visual spatial construction. Psychometric properties of the mMMS have been published previously. ${ }^{36}$ The maximum score is 57 , with higher scores indicating better cognition.

Depression. The seven-item depression subscale of the Brief Symptom Inventory ${ }^{37}$ was used to evaluate level of depression. Participants were asked to indicate on a 5point Likert scale how frequently they were bothered by various symptoms of depressed mood. A participant's depression score was the summed frequency of all items (0-35), with higher scores indicating worse depression. 


\section{Statistical Analyses}

All primary variables of interest (subjective word-finding difficulty and leisure activity estimates) were measured according to participant self-report. As such, the extent to which participant reports mapped onto caregiver reports was first assessed. The relationship between participant and caregiver reports of participant wordfinding difficulty was evaluated using the phi coefficient, a measure of association between two binary variables. Bivariate correlations were used to examine the relationship between participant and caregiver reports of the participant's frequency and enjoyment of social and nonsocial activities, and paired sample $t$-tests were used to characterize discrepancies between the two reporting sources.

Multiple linear regressions were used to examine the effect of subjective word-finding on four outcome variables that the participant reported (social activity frequency, social activity enjoyment, nonsocial activity frequency, nonsocial activity enjoyment). Covariates were included in regression models if they were found to be significantly related to leisure activities or word-finding ratings in preliminary univariate analyses $(P<.05)$. Bivariate correlations were used to measure the association between continuous variables (e.g., leisure activity measures, age, education, depression, and dependence), point biserial correlations were used to measure the association between the dichotomous word-finding variable and the continuous covariates, and the phi coefficient was used to measure the association between two dichotomous variables (subjective word-finding and sex). As a confirmatory procedure, the same regression model was tested using caregiver reports of social activity substituted as the outcome measure. A Steiger's Z test was performed to determine whether the univariate correlation between subjective word-finding difficulty and social leisure activity was significantly greater than the correlation between subjective word-finding difficulty and nonsocial activity. Finally, the relationship between subjective word-finding rating and objective word-finding ability was examined using partial correlations. Significant correlates were entered into a regression model with subjective word-finding difficulty to assess the relative effect of objective and subjective language difficulty on social leisure activities. For regression models, the standardized coefficient $(\beta)$ or the unstandardized coefficient $(b)$ with standard error ( $S E$ B) are reported.

\section{RESULTS}

\section{Relationship Between Participant and Caregiver Reports}

Reports of word-finding difficulty that participants supplied were significantly correlated with caregiver reports (correlation coefficient $(r)=0.36, P<.001$ ), suggesting that participants were accurate in assessing their own language ability. Furthermore, all indices of social and nonsocial activity (frequency and enjoyment) showed significant correlations between participant and caregiver reports (all $P<.001$ ), with the strength of relationships being moderate to large. Descriptive statistics for the participant and caregiver reports and the correlation coefficients describing their relationship are shown in Table 3. Participant-reported frequency $(t \quad(227)=3.0, P=.003)$ and enjoyment $(t(220)=4.2, P<.001)$ of their own social activities was significantly higher than caregiver reports of participant activities. Similarly, participantreported frequency $(t(219)=4.5, P<.001)$ and enjoyment $(t(204)=5.5, P<.001)$ of nonsocial activities were also significantly higher than caregiver reports. Hence, although participants rated their participation in leisure activities more frequently and more positively than their caregivers, reporting bias did not affect one type of activity more than the other.

\section{Predictors of Leisure Activities}

Subjective word-finding difficulty was correlated higher depression scores $(r=0.19, P=.001)$ but not with any other covariate measures. With the exception of sex, all covariates were significantly correlated with one or more of the leisure activity measures (all $P<.05$ ). As such, each regression model included word-finding ratings, age, education, dependence, mMMS score, and depression as predictors. Study site was entered as a nuisance covariate in each model to avoid potential differences in measurement procedures or the meaning of constructs (e.g., social activity) across study locations.

\section{Participant-Reported Activity Engagement}

Social Activities. The overall model predicting participant frequency of social leisure activities was significant $\left(F_{7,217}=5.72, P<.001\right)$. Subjective word-finding difficulty, dependence, and depression emerged as significant independent predictors of participant-reported social activity frequency (all $P<.04$ ). The full model of social activity enjoyment was also significant $\left(F_{7,213}=6.21, P<.001\right)$. Subjective word-finding difficulty, dependence, and depression each accounted for a unique proportion of variance (all $P<.04)$. Results from these analyses are shown in Table 4 .

Table 3. Participant and Caregiver Reports of Leisure Activities

\begin{tabular}{|c|c|c|c|c|}
\hline \multirow[b]{2}{*}{ Measure } & $\begin{array}{l}\text { Participant } \\
\text { Report }\end{array}$ & $\begin{array}{l}\text { Caregiver } \\
\text { Report }\end{array}$ & \multirow[b]{2}{*}{$\begin{array}{l}\text { Correlation } \\
\text { Coefficient }\end{array}$} & \multirow[b]{2}{*}{$P$-Value } \\
\hline & \multicolumn{2}{|c|}{$\begin{array}{c}\text { Mean } \pm \text { Standard } \\
\text { Deviation }\end{array}$} & & \\
\hline $\begin{array}{l}\text { Frequency of } \\
\text { social activities } \\
\text { (out of 12) }\end{array}$ & $6.4 \pm 2.1$ & $6.0 \pm 1.9$ & .51 & $<.001$ \\
\hline $\begin{array}{l}\text { Enjoyment of } \\
\text { social activities } \\
\text { (out of } 6 \text { ) }\end{array}$ & $4.3 \pm 1.2$ & $4.0 \pm 1.3$ & .52 & $<.001$ \\
\hline $\begin{array}{l}\text { Frequency of } \\
\text { nonsocial activities } \\
\text { (out of 20) }\end{array}$ & $11.0 \pm 3.2$ & $10.1 \pm 3.0$ & .53 & $<.001$ \\
\hline $\begin{array}{l}\text { Enjoyment of } \\
\text { nonsocial activities } \\
\text { (out of } 10 \text { ) }\end{array}$ & $6.6 \pm 1.8$ & $5.9 \pm 1.9$ & .45 & $<.001$ \\
\hline
\end{tabular}


Nonsocial Activities. The overall model predicting participant-reported nonsocial activity frequency was significant $\left(F_{7,212}=5.16, P<.001\right)$, but only age emerged as a significant independent predictor $(P<.001)$. Age and depression were predictors of self-reported nonsocial activity enjoyment $\left(F_{7,206}=3.35, P=.002\right)$. Results from regression models of nonsocial outcomes are shown in Table 5.

Comparing Social and Nonsocial Activity. Results from the regression analyses revealed a selective effect of subjective word-finding difficulty on frequency and enjoyment of social activities. A Steiger's $\mathrm{Z}$ test was used to compare the magnitudes of the correlation coefficients to confirm that the strength of association between subjective word-finding difficulty and social leisure activity was reliably different from the relationship between subjective word-finding difficulty and nonsocial activity. Composite social and nonsocial activity scores were computed, which included the sum of the frequency and enjoyment measures. As expected, the correlation between subjective word-finding and the social activity composite $(r=-0.16)$ was significantly larger than its correlation with the nonsocial activity composite $(r=0.01$; Steiger's $Z=2.14$, $P=.02)$.

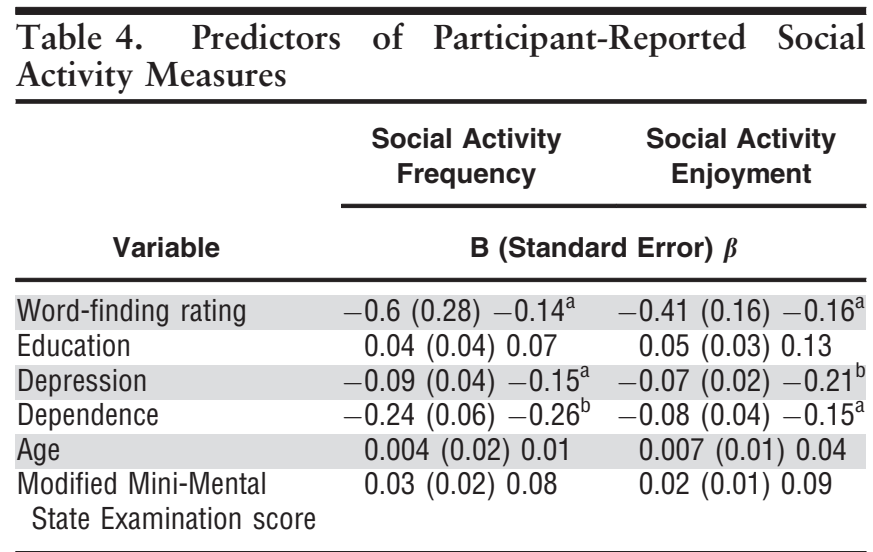

Coefficient of determination $\left(r^{2}\right)=0.16$ for social activity frequency; $r^{2}=0.17$ for social activity enjoyment. Study site was also entered as a covariate.

${ }^{\mathrm{a}} P<.05,{ }^{\mathrm{b}} .01$.

Table 5. Predictors of Participant-Reported Nonsocial Activity Measures

\begin{tabular}{lcc}
\hline & $\begin{array}{c}\text { Nonsocial Activity } \\
\text { Frequency }\end{array}$ & $\begin{array}{c}\text { Nonsocial Activity } \\
\text { Enjoyment }\end{array}$ \\
\cline { 2 - 3 } \multicolumn{1}{c}{ Variable } & \multicolumn{3}{c}{ B (Standard Error) $\boldsymbol{\beta}$} \\
\hline Word-finding rating & $-0.4(0.41)-0.06$ & $0.004(0.24) 0.001$ \\
Education & $0.07(0.07) 0.08$ & $0.06(0.04) 0.10$ \\
Depression & $-0.09(0.06)-0.10$ & $-0.08(0.04)-0.14^{\mathrm{a}}$ \\
Dependence & $-0.09(0.10)-0.07$ & $-0.01(0.06)-0.01$ \\
Modified Mini-Mental & $0.05(0.04) 0.10$ & $0.02(0.02) 0.08$ \\
State Examination score & $-0.10(0.03)-0.24^{\mathrm{b}}$ & $-0.04(0.02)-0.17^{\mathrm{a}}$ \\
Age & $-0.02)$ \\
\hline
\end{tabular}

Coefficient of determination $\left(r^{2}\right)=0.15$ for nonsocial activity frequency; $r^{2}=0.10$ for nonsocial activity enjoyment. Study site was also entered as a covariate.

${ }^{\mathrm{a}} \mathrm{P}<.05,{ }^{\mathrm{b}} .01$.

\section{Caregiver-Reported Social Activity Engagement}

The same predictor variables were used in a regression model testing caregiver ratings of participant participation in social leisure activities. The overall model estimating caregiver reports of participants' frequency of social activities was significant $\left(F_{7,212}=6.65, P<.001\right.$, coefficient of determination $\left.\left(r^{2}\right)=0.18\right)$. Consistent with the above findings, participant-reported word-finding difficulty was a unique predictor of social activity participation as reported by caregivers $(\beta=-0.15, t=-2.35, P=.02)$. mMMS $(\beta=0.15, t=-2.24, P=.03)$ and dependence $(\beta=-0.22$, $t=-3.28, P<.001)$ ratings were also uniquely related to caregiver estimates of participant social activity.

\section{Subjective vs Objective Word-Finding Ability}

The relationship between subjective word-finding reports and objective performance on naming, letter fluency, and category fluency tasks was examined to determine the extent to which participant complaints regarding wordfinding difficulty mapped to actual decline in word retrieval. Because only raw scores from the neuropsychological tests were available, relationships were tested using partial correlations adjusted for age, sex, and education. Endorsement of word-finding difficulty was associated with poorer performance on letter fluency $(r=-0.18, P=.02)$ and category fluency $(r=-0.14, P=.05)$ but was not associated with performance on the naming task $(r=-0.06, P=.40)$.

To assess the relative contributions of objective and subjective word-finding difficulty on social behavior, subjective word-finding reports, both fluency measures, and the demographic variables were entered into a regression equation predicting a social activity composite score (frequency plus enjoyment). The model adequately predicted social activity $\left(F_{6,181}=5.80, P<.001, r^{2}=0.16\right)$, and subjective word-finding ratings $(\beta=-0.17, t=-2.39$, $P=.02)$ and letter fluency $(\beta=0.24, t=-2.86, P=.005)$ were independent predictors of social activity.

\section{DISCUSSION}

Despite the frequency of word-finding difficulty in healthy aging and dementia, the effect of subjective language complaints on various late-life outcomes has not been extensively examined. It is intuitive that failures of language expression, particularly in the ability to access known words and names, would weaken older adults' confidence in conversation, ${ }^{6-9}$ diminishing their desire to seek out socially stimulating experiences. In support of this hypothesis, these data are the first to demonstrate an independent effect of perceived word-finding problems on the frequency and enjoyment of socially oriented leisure activities in individuals with mild to moderate AD.

Multiple factors may contribute to the salience of subjective word-finding difficulty as a predictor of social leisure activities. First, although dementia is associated with lack of insight into behavioral and memory symptoms, recent evidence suggests that individuals with $\mathrm{AD}$ may provide accurate or underestimated assessments of their naming ability. ${ }^{38}$ Therefore, individuals with early $\mathrm{AD}$ may be "hyperaware" of word retrieval difficulty despite 
lacking insight into memory decline. The current data supported this idea, in that participant-reported word-finding difficulty strongly correlated with caregiver reports and was associated with poorer performance on verbal fluency tasks. These findings are indicative of relatively preserved insight into word-finding deficits in $\mathrm{AD}$, at least during the mild to moderate stage. The fact that subjective word-finding complaints were associated with lower social engagement independent of the effect of objective word-finding ability further emphasized the importance of awareness in influencing social behavior. Symptoms that restrict communication ability may especially disturb individuals with $\mathrm{AD}$. One recent study demonstrated that participants with mild cognitive impairment and mild $\mathrm{AD}$ were more distressed about self-detected problems in cognitive skills needed for social interaction than other cognitive domains. ${ }^{39}$ Overall, the high frequency of participants' self-reported word-finding difficulty, their intact or exaggerated awareness of word retrieval difficulty, and their heightened distress over symptoms that affect social interaction may all contribute to the relationship between subjective word-finding problems and likelihood of (dis)engaging in socially oriented leisure activities.

Other related variables, including depression, dependence level, global cognitive ability, and age, cannot account for the relationship between subjective wordfinding difficulty and social activity. Most strikingly, subjective word-finding difficulty remained a significant predictor of social activity engagement even after controlling for depression, which was a correlate of subjective word finding and social leisure activities. The link between subjective word-finding difficulty and depression converges with previous studies documenting an association between subjective cognitive complaints and depressive symptomology, ${ }^{40,41}$ an association that has a number of potential explanations. For example, individuals who are depressed may overendorse cognitive problems because they are more focused on negative aspects of life, independent of awareness of cognitive changes. Conversely, older adults may develop depression because of their accurate detection of genuine cognitive decline. Despite the empirical links between subjective cognition, depression, and leisure activities, participant perception of word-finding difficulty remained a unique predictor of social activity in addition to what was explained by depression. Even more convincingly, caregiver reports corroborated the relationship between participants' subjective word-finding difficulty and their social activity. Hence, the relationship cannot be attributed to a negative self-report bias (e.g., individuals who report word-finding complaints and high depressive symptoms thereby underreporting their social activity).

Further support for a unique relationship between expressive language concerns and social activity stems from the fact that subjective word-finding difficulty was not related to nonsocial activities. Instead, age and depression predicted nonsocial activities. These results suggest that the association between word-finding complaints and social activity participation is related to the specific cognitive demands of social activity (interacting with others) and the individuals' insight into their communicative ability, as opposed to a general mood construct shared by both variables.
The present findings expand upon one recent study reporting an association between self-reported word-finding difficulty and older adults' living environment. ${ }^{40}$ Specifically, it was found that word-finding complaints were more common in older adults who lived alone than in those who lived with family or spouses. Although there are important methodological differences between the two studies (their participants were elderly adults without dementia, and their "living environment" assessment was a less-direct measure of social interaction than the leisure activity scale used here), two sources now support a relationship between social interaction and frequency of subjective word-finding complaints in older adulthood. Nevertheless, the directionality of this association has two alternative explanations. Contrary to the theory of the current study that individuals with perceived word-finding problems actively avoid social situations, the other study attributed its findings to a protective effect of social stimulation on objective word retrieval abilities. In other words, maintaining social interaction might reduce actual language problems in late life, resulting in fewer subjective complaints. There is evidence to suggest that measures of social engagement, such as social network size, mitigate the effects of aging and neurodegeneration on global cognitive function, ${ }^{40,41}$ which may be true of the language domain as well.

Related to this hypothesis, the other study found that word-finding complaints were related to some measures of objective language ability, most consistently category fluency, which was also marginally associated with household company. In the current sample, subjective word-finding complaints were associated with poorer performance on both verbal fluency measures but were not linked to measures of global cognition or object naming. Hence, there is converging evidence that word-finding complaints in healthy older adults and individuals with mild to moderate $\mathrm{AD}$ are related to poorer performance on some indices of actual word retrieval ability. Still, the directionality of the relationship between social engagement and subjective word-finding complaints remains unclear. Future research should explore causal or longitudinal models to determine whether sustained social engagement indeed protects against objective and subjective language decline or whether perceived language decline precipitates social disengagement.

This study had a number of methodological limitations. First, neither the word-finding variable nor the leisure activity variables was measured with great precision. Eliciting word-finding complaints using yes-or-no response limits the ability to evaluate levels of complaint severity or degree of distress regarding these complaints. Furthermore, frequency and enjoyment of leisure activity measures also had restrictive response scales, and all measures relied on participant self-report, which has obvious limitations in a population with memory impairment. Nonetheless, the correspondence between participant and caregiver reports and the relationship between the objective and subjective word-finding measures allows for some degree of confidence regarding the validity of the scales. In addition, differences in general difficulty between the social and nonsocial activities were not formally evaluated. It is possible that social activity engagement is a more-sensitive early indicator of overall cognitive impairment, making it more likely to be linked to subjective cognitive complaints. This 
concern was minimized by the fact that social and nonsocial activity scores were similarly associated with measures of disease severity and cognitive status in the correlation analyses, and both regression models included these variables as covariates. Finally, although it was hypothesized that the association between social activity frequency and subjective word-finding difficulty was due to the individuals' volitional withdrawal from social interaction, it may also be linked to the caregivers' desire to protect loved ones from social embarrassment. In other words, caregivers of individuals with profound word-finding difficulty might discourage them from participating in socially oriented activities. Although this possibility cannot be excluded entirely, participant word-finding ratings also predicted their self-rated enjoyment of leisure activities, a measure that caregiver actions presumably should not bias.

\section{CONCLUSION}

In summary, the present study suggests that subjective word-finding difficulty is an important predictor of social activity engagement in AD. These findings may have significant clinical and health implications for individuals with dementia. Clinicians should seriously consider subjective language complaints that participants and caregivers report. A failure to evaluate subjective language complaints could result in social withdrawal symptoms, threatening quality of life and increasing caregiver burden. More importantly, lack of social interaction may ultimately exacerbate language symptoms over time. Emphasizing the extensiveness of word-finding complaints in older adulthood and dementia may reduce anxiety surrounding this distressing cognitive phenomenon.

\section{ACKNOWLEDGMENTS}

The Predictors Study is supported by National Institute on Aging (NIA) Grant R01 AG007370 awarded to Dr. Stern. Drs. Farrell and Zahodne are supported by NIA Grant T32 AG00026.

Conflict of Interest: The editor in chief has reviewed the conflict of interest checklist provided by the authors and has determined that the authors have no financial or any other kind of personal conflicts with this paper.

Author Contributions: Farrell: study concept and design, analysis and interpretation of data, manuscript preparation, final approval of manuscript. Zahodne, Stern, Cosentino: analysis and interpretation of data, critical review of manuscript, final approval of manuscript. Dorrejo, Yeung: Acquisition of data, critical review of manuscript, final approval of manuscript.

Sponsor's Role: The content is solely the responsibility of the authors and does not necessarily represent the official views of the National Institutes of Health. The sponsors had no role in the study design or data interpretation.

\section{REFERENCES}

1. Derouesne C, Dealberto MJ, Boyer P et al. Empirical evaluation of the Cognitive Difficulties Scale for assessment of memory complaints in general practice: A study of 1628 cognitively normal subjects aged $45-75$ years. Int J Geriatr Psychiatry 1993;8:599-607.
2. Lovelace EA, Twohig PT. Healthy older adults' perceptions of their memory functioning and use of mnemonics. Bull Psychon Soc 1990;28:115-118.

3. Maylor EA. Proper name retrieval in old age: Converging evidence against disproportionate impairment. Aging Neuropsychol Cogn 1997; 4: 211-226.

4. Snitz BE, Morrow LA, Rodriguez EG et al. Subjective memory complaints and concurrent memory performance in older patients of primary care providers. J Int Neuropsychol Soc 2008;14:1004-1013.

5. Burke DM, MacKay D, Worthley JS et al. On the tip of the tongue: What causes word finding failures in you and older adults? J Mem Lang 1991;30:542-579.

6. Abrams L. Tip-of-the-tongue states yield language insights. Am Sci 2008;96:234-239.

7. Burke DM, Shafto MA. Aging and language production. Curr Dir Psychol Sci 2004;13:21-24.

8. Burke DM, Shafto MA. Language and aging. In: Craik FIM, Salthouse TA, eds. The Handbook of Aging and Cognition. New York, NY: Psychology Press, 2008, pp 373-443.

9. Ryan EB, See SK, Meneer WB et al. Age-based perceptions of language performance among younger and older adults. Comm Res 1992;19:423-443.

10. Astell AJ, Harley TA. Tip-of-the-tongue states and lexical access in dementia. Brain Lang 1996;54:196-215.

11. Cappa SF, Binetti G, Pezzini A et al. Object and action naming in Alzheimer's disease and frontotemporal dementia. Neurology 1998;50:351-355.

12. Cotelli M, Manenti R, Cappa SF et al. Transcranial magnetic stimulation improves naming in Alzheimer disease patients at different stages of cognitive decline. Eur J Neurol 2008;15:1286-1292.

13. Cotelli M, Manenti R, Brambilla M et al. Naming ability changes in physiological and pathological aging. Front Neurosci 2012;6:120.

14. Reilly J, Martin N, Grossman M. Verbal learning in semantic dementia: Is repetition priming a useful strategy? Aphasiology 2005;19:329-339.

15. Geerlings MI, Jonker C, Bouter LM et al. Association between memory complaints and incident Alzheimer's disease in elderly people with normal baseline cognition. Am J Psychiatry 1999;156:531-537.

16. Wang L, van Belle G, Crane PK et al. Subjective memory deterioration and future dementia in people aged 65 and older. J Am Geriatr Soc 2004;52:2045-2051.

17. Amariglio RE, Becker JA, Carmasin J et al. Subjective cognitive complaints and amyloid burden in cognitively normal older individuals. Neuropsychologia 2012;50:2880-2886.

18. Jessen F, Feyen L, Freymann $\mathrm{K}$ et al. Volume reduction of the entorhinal cortex in subjective memory impairment. Neurobiol Aging 2006;27:1751-1756.

19. Mosconi L, De Santi S, Brys M et al. Hypometabolism and altered cerebrospinal fluid markers in normal apolipoprotein E E4 carriers with subjective memory complaints. Biol Psychiatry 2008;63:609-618.

20. Saykin AJ, Wishart HA, Rabin LA et al. Older adults with cognitive complaints show brain atrophy similar to that of amnestic MCI. Neurology 2006;67:834-842.

21. van Norden AG, Fick WF, de Laat KF et al. Subjective cognitive failures and hippocampal volume in elderly with white matter lesions. Neurology 2008;71:1152-1159.

22. Hoe J, Katona C, Roch B et al. Use of the QOL-AD for measuring quality of life in people with severe dementia-the LASER-AD study. Age Ageing 2005;34:130-135.

23. Logsdon RG, McCurry SM, Teri L. Evidence-based interventions to improve quality of life for individuals with dementia. Alzheimers Care Today 2007;8:309-318.

24. Wang HX, Jin $\mathrm{Y}$, Hendrie $\mathrm{HC}$ et al. Late life leisure activities and risk of cognitive decline. J Gerontol A Biol Sci Med Sci 2013;68A:205-213.

25. Verghese J, Lipton RB, Katz MJ et al. Leisure activities and the risk of dementia in the elderly. N Engl J Med 2003;348:2508-2516.

26. Teri L, Logsdon RG, Uomoto J et al. Behavioral treatment of depression in dementia patients: A controlled clinical trial. J Gerontol B Psychol Sci Soc Sci 1997;52B:159-166.

27. Teri L, McCurry SM, Logsdon R et al. Training community consultants to help family members improve dementia care: A randomized controlled trial. Gerontologist 2005; 45:802-811.

28. Logsdon RG, Teri L. The Pleasant Events Schedule-AD: Psychometric properties and relationship to depression and cognition in Alzheimer's disease patients. Gerontologist 1997;37:40-45.

29. Siedlecki KL, Tatarina O, Sanders L et al. Comparison of patient and caregiver reports of patient activity participation and its relationship to mental health in patients with Alzheimer's disease. J Gerontol B Psychol Sci Soc Sci 2009;64B:687-695.

30. Stern Y, Folstein M, Albert M et al. Multicenter study of predictors of disease course in Alzheimer disease (the "Predictors Study"). I. Study design, 
cohort description, and intersite comparisons. Alzheimer Dis Assoc Disord 1993;7:3-21.

31. Folstein MF, Folstein SE, McHugh PR. 'Mini-mental state'. A practical method for grading the cognitive state of patients for the clinician. J Psychiatr Res 1975;12:189-198.

32. Teri L, Logsdon RG. Identifying pleasant activities for Alzheimer's disease patients: The pleasant events schedule-AD. Gerontologist 1991;31:124-127.

33. Kaplan E, Goodglass H, Weintraub S. Boston Naming Test. Philadelphia, PA: Lea \& Febiger, 1983.

34. Benton AL, Hamsher K, Sivan AB. Manual for the Multilingual Aphasia Examination, 3rd Ed. Iowa City, IA: AJA Associates Inc, 1994.

35. Stern Y, Albert SM, Sano M et al. Assessing patient dependence in Alzheimer's disease. J Gerontol 1994;49:M216-M222.

36. Stern Y, Sano M, Paulson J et al. Modified Mini-Mental State Examination: Validity and reliability. Neurology 1987;37:179.
37. Derogatis LR, Melisaratos N. The Brief Symptom Inventory: An introductory report. Psychol Med 1983;13:595-605.

38. Banks S, Weintraub S. Self-awareness and self-monitoring of cognitive and behavioral deficits in behavioral variant frontotemporal dementia, primary progressive aphasia and probable Alzheimer's disease. Brain Cogn 2008;67:58-68.

39. Maki Y, Amari M, Yamaguchi T et al. Anosognosia: Patients' distress and self-awareness of deficits in Alzheimer's disease. Am J Alzheimers Dis Other Demen 2012;27:339-345.

40. Martins I, Mares I, Stilwell P. How subjective are subjective language complaints. Eur J Neurol 2012;19:666-671.

41. Slavin MJ, Brodaty H, Kochan NA et al. Prevalence and predictors of "subjective cognitive complaints" in the Sydney Memory and Ageing Study. Am J Geriatr Psychiatry 2010;18:701-710. 